\title{
LA NOCIÓN DE FAMILIA DE NIÑAS Y NIÑOS PREESCOLARES COSTARRICENSES Y CENTROAMERICANOS, EN COSTA RICA
}

\author{
Doris Rocío Arce Villalobos ${ }^{1}$ \\ Alejandra Carballo León ${ }^{2}$ \\ Karla Alejandra Castro Castro ${ }^{3}$ \\ Zulay Pereira Pérez.
}

\section{Resumen}

La División de Educación Básica del CIDE, Universidad Nacional, realizó una investigación cuyos resultados se constituyen en un aporte, para que el conocimiento de los factores relacionados con la diversidad cultural existente dentro de las aulas, no se considere como un obstáculo en los procesos de construcción de conocimientos. En este sentido, se parte de la idea de que acercarse a comprender las nociones de familia de las niñas y los niños, es inherente al reto que cada educador debe asumir si está dis- puesto a apropiarse de una actitud de compromiso en la promoción de procesos educativos contextualizados, que tengan como eje las diferencias individuales y culturales de los estudiantes.

\section{Abstract}

Present research results obtained by the Department of Basic Education of the Universidad Nacional (CIDE) contribute to understand that factors related with cultural diversity within the classroom do not represent an obstacle in the

\footnotetext{
${ }^{1}$ Licenciada en educación Preescolar y docente en esta misma especialidad.

${ }^{2}$ Licenciada en educación Preescolar y docente en I Ciclo de la Educación General Básica.

${ }^{3}$ Licenciada en educación Preescolar y bachiller en Psicología.

${ }^{4}$ Catedrática de la Universidad Nacional. Máster en Psicología de la Ĺniversidad de Costa Rica. Excordinadora e Investigadora del Programa de Investigación en Epistemología Genética y Educación del IMEC, Universidad de Costa Rica. Exdirectora de la División de Educación Básica del CIDE-UNA. Actualmente se desempeña como docente e investigadora en el Centro de Investigación y Docencia en Educación. Tiene publicaciones en el campo de la Psicología.
} 
process of knowledge construction. Accordingly, this study sustains the idea that educators need to comprehend the children's notion of family as part of the challenge they assume if they are willing to develop a committed approach towards the development of a contextoriented learning process, based on the students' individual and cultural differences.

Palabras claves: diversidad cultural, procesos educación y familia .

$\mathrm{H}$ asta hace algunos años, la población estudiantil en las aulas costarricenses se caracterizaba por ser predominantemente de origen costarricense, por lo cual no se contemplaba, en forma explícita, la multiculturalidad como un eje transversal en la elaboración y desarrollo de los programas de estudio. Sin embargo, actualmente y como producto de los cambios socioeconómicos vividos por muchos países latinoamericanos, el sistema educativo ha tenido que enfrentar una serie de situaciones o fenómenos (en este caso, migratorios) antes no previstos y que, sin duda, tienen grandes repercusiones e implicaciones en los procesos educativos.

Dado que las políticas educativas deben procurar construir ambientes educativos que contemplen la multiculturalidad desde una perspectiva positiva, en la División de Educación Básica del CIDE, Universidad Nacional, se realizó una investigación cuyos resultados se constituyen en un aporte, para que el conocimiento de los factores relacionados con la diversidad cultural existente dentro de las aulas, no se considere como un obstáculo en los procesos de construcción de conocimientos, sino como una dimensión valiosa que puede enriquecerlos.

En este sentido, se parte de la idea de que acercarse a comprender las nociones de familia de las niñas y los niños, es inherente al reto que cada educador debe asumir si está dispuesto a apropiarse de una actitud de compromiso en la promoción de procesos educativos contextualizados que tengan como eje las diferencias individuales y culturales de los estudiantes. Este compromiso también constituyó la base de la investigación titulada "La noción de familia que tienen los niños costarricenses y extranjeros centroamericanos que asisten a un jardín de niños público" (Arce, Carballo, Castro y Pereira, 2004) y de cuyos resultados se formula el presente artículo.

Es pertinente, al analizar la noción de familia de niñas y niños costarricenses y centroamericanos, abordar tangencialmente los procesos migratorios que se han dado en Costa Rica. Según Ebanks (1993), la migración se define como "(...) un traslado o cambio de residencia que supone abandonar 
una zona política administrativa e ingresar en otra durante un período prolongado de tiempo" (p. 38).

Los factores socioeconómicos son los aspectos más influyentes en la comprensión de los procesos migratorios de cualquier nación. Las grandes problemáticas que una población puede enfrentar en su país de origen son el motor que impulsa el traslado de ésta hacia lugares con condiciones más motivantes y favorables.

Brenes (1999) argumenta que las investigaciones con respecto a las poblaciones inmigrantes en Costa Rica, empiezan a tener auge durante los años ochenta. Algunas de ellas trataron de estimar el saldo migratorio para los primeros años de la década, otras se refieren a las características y formas de vida de los refugiados. Es pertinente señalar que muchos de los estudios se basaron en la población nicaragüense.

En el caso de Centroamérica, las condiciones socioeconómicas imperantes han convertido a Costa Rica, desde hace varios años, en el principal país receptor de inmigrantes. En su mayoría, estos son de origen nicaragüense, salvadoreño y estadounidense, aunque existen otros inmigrantes de habla hispana. Cabe agregar que las estadísticas brindadas por la Facultad Latinoamericana de Ciencias Sociales (FLACSO, 1999), señalan que el $91 \%$ del universo que se acogió al régimen de amnistía son inmigrantes originarios de Nicaragua.

Además, en la última década, se nota el aumento de la población colombiana en el país. La Dirección General de Migración y Extranjería (citado por Varela, 2003) establece que para "octubre del 2002, el total de solicitudes de refugio y residentes (permanentes y temporales) tramitadas ascendió a la suma de 9443 colombianos que estaban en Costa Rica en condiciones regulares" (p. 3).

Los procesos migratorios inciden directamente en la constitución de los grupos que llegan a las aulas del sistema educativo costarricense. Por esta razón es que se requiere un mayor conocimiento acerca de las poblaciones estudiantiles, sus creencias, concepciones, entre otros aspectos, a fin de favorecer sus procesos pedagógicos.

Como se señaló anteriormente, el fenómeno del ingreso masivo de la población extranjera en Costa Rica ha sido una constante en los últimos años. La búsqueda de óptimos servicios educacionales, condiciones de mejor atención a la salud y demás necesidades esenciales como la vivienda, son parte de las motivaciones que impulsan a las familias a trasladarse de un país a otro. En el caso de las familias inmigrantes, estas aspiraciones se convierten en demandas para el Estado costarricense. 
La escuela, como institución social, debe asumir parte de esas demandas por ser, a la vez, un ente activo en la configuración de cambios sociales; por lo tanto, puede encontrarse una finalidad común entre la escuela y la familia: el desarrollo integral del niño, a pesar de las características heterogéneas que muestra la población. Esta heterogeneidad una situación especial y enriquecedora en las aulas costarricenses; la multiculturalidad se convierte así en una característica de la población que asiste a las escuelas de Costa Rica. Dentro de este ámbito, el trabajo docente debe enfocar las características socioculturales de cada uno de sus estudiantes; y dentro de éstas, el tema de la familia y las relaciones intrafamiliares constituye un ámbito de nuevas realidades y demandas que deben ser asumidas por los procesos educativos de carácter formal.

Contar con investigaciones en el ámbito costarricense que abordan temáticas referentes a variados conceptos que poseen los estudiantes, puede constituirse en un apoyo para los docentes que día tras día se enfrentan a situaciones que les muestran un panorama muy diverso y multicultural en sus aulas. Por esta razón, el estudio sirve como apoyo a la práctica profesional de los docentes, dado que se acerca al conocimiento de las nociones de familia desde la perspectiva de los preescolares en este caso particular.

Los movimientos migratorios internos y externos que experimentan las comunidades constantemente, han producido en la sociedad gran diversidad cultural. De ahí que para acercarse a la comprensión de estos procesos sociales, es necesario partir de una construcción conceptual de la cultura.

Dengo (1995) precisa que los seres humanos viven en conjuntos; el hombre no se entiende aislado sino como un ser social. Para que exista una sociedad, se necesita que varias personas habiten un determinado territorio geográfico, tener un sentido de pertenencia a un mismo grupo, aceptar cierto tipo de organización política y un modo social de vida con el que estén identificados y que sea compartido por todos los miembros de ese grupo. La autora menciona que ese modo social de vida se comprende bajo los términos de comunidad o cultura del grupo, la cual abarca muy complejas y diversas manifestaciones.

Añade además que uno de los rasgos específicos del ser humano es crear cultura. "La cultura se concibe, en este sentido, como todo lo que el hombre ha producido, y produce en el orden material y espiritual" (Dengo, 1995, p. 21).

Por su parte, Strivens (citado por MEP, 2000-2001) propone el concepto de cultura como: 
...aquellos fenómenos que crean un sentido de identidad entre un grupo particular: un lenguaje o dialecto, fe religiosa, identidad étnica y localización geográfica. Se trata de factores subyacentes que dan lugar a comprensión, reglas y prácticas compartidas que gobiernan el desarrollo de la vida diaria. El comportamiento cultural es comportamiento aprendido, pero tan profunda y completamente aprendido que pasa a ser en gran medida inconsciente (p. 82).

De lo anterior, se deduce que la cultura no es innata, sino más bien, se construye en el contexto social. Para reforzar la idea anterior, Recasens (2001) expone que el ser humano pasa por un proceso llamado endoculturación en el cual mediante las experiencias socializadoras por el contacto con otros grupos, conforman una personalidad única y articulable con los de su propia cultura.

Dengo (1995) señala que la cultura se caracteriza por ser dinámica, y que al igual que la sociedad crece y se modifica en el curso de la historia. Algunas veces le ha tocado abandonar patrones que en determinados tiempos han tenido vigencia, pero que después han perdido su función en relación con la evolución y los cambios de la sociedad.

Según la autora, la cultura comprende dos expresiones o modalidades. Específicamente:

- La cultura sistematizada o herencia cultural de la historia universal o particular del país o de la sociedad en concreto: la cual está constituida por los productos que la sociedad ha sistematizado y acumulado a lo largo de la historia.

- La cultura cotidiana o emergente: se refiere a los hábitos y costumbres de la comunidad, enriquecidos continuamente por el cambio social, las habilidades artesanales que se practican dentro del grupo y, por el vocabulario y las modas que se crean, se transmiten, y que la colectividad adopta, basada principalmente, en los medios de comunicación.

De un modo particular, la autora postula que la comprensión de la cultura como modo de vivir de una comunidad, implica que los patrones culturales se afiancen en el grupo social que los aprende, los comparte, se identifica con ellos y los transmite. Cabe destacar que en este proceso, la educación desempeña un papel trascendental. Por ello, muchos movimientos renovadores de la educación y sobre todo, de la escolarización, incluyen entre sus máximas acercar la escuela a la vida y de ahí al medio en el que los escolares conviven cotidianamente. 
Al respecto, García, Pulido y Montes (2002) argumentan que la cultura se transmite por medio de diferentes mecanismos y diversos agentes. Añaden los autores que una parte de la cultura se "autotransmite" en función de su propia dinámica; mientras que la otra parte es transmitida en instituciones especializadas que enfatizan los aspectos más formales o académicos de ella, pues en gran parte sólo sirven para la escuela.

En esta misma tendencia, Dengo (1995) considera que al transmitir la herencia cultural, la educación se convierte en un hilo conductor que posibilita la supervivencia de la cultura, o sea, la continuidad histórica de cada colectividad y de sus modos de vida social. Por esta razón, "la sociedad necesita de la educación para mantenerse con la historia, es decir, para que los patrones sociales y culturales que ella misma ha forjado sobrevivan en el tiempo y se conserven y, con ello, la misma sociedad perviva" (p. 28).

Es pertinente señalar que la cultura al igual que la educación, se encuentra permeada por elementos presentes en la sociedad, por lo que la diversidad, como fenómeno universal, incrementa la existencia de sociedades étnicamente pluralistas.

Según Meléndez (2000) la diversidad cultural, se evidencia cuando se reconoce, valora, aporta y aprende de las particularidades que identifican a los sujetos como pertenecientes a una comunidad. La diversidad es una condición de la vida en sociedad, “(...) cuyos procesos vitales se relacionan entre sí y se desarrollan en función de los factores culturales de un mismo ambiente. Donde, tanto relación como variedad aseguran y potencian la vida de todos los habitantes de esa comunidad" (p. 4).

Dado que el estudio aborda el análisis de la noción de familia de niños costarricenses y extranjeros, es necesario tomar en cuenta los procesos migratorios que se dan en el país. Al conceptuar la migración, Azofeifa, Céspedes, Monge y Vidal (2001), consideran que “(...) se presenta aquí el movimiento de grupos de personas que se trasladan de su lugar de origen a otro punto geográfico para residir en él" (p. 18); se puede hablar entonces de la migración como un hecho históricoy un proceso social que caracteriza a los seres vivos.

Los movimientos migratorios según Azofeifa et al. (2001) se pueden agrupar en dos tipos: los internos y los externos; los primeros se refieren a los desplazamientos de población dentro de los límites territoriales y los segundos a la salida de población costarricense al exterior, así como el ingreso de extranjeros a dicho territorio.

Comprender estos movimientos migratorios implica analizar las diferentes causas que los producen. Estos autores citan dos posibles circunstancias que 
provocan la movilización de población: las que son producidas por la naturaleza, entre ellas factores climáticos o catástrofes naturales; y las que son producidas por la acción de las personas, como los conflictos políticos, religiosos, económicos, guerras, entre otros.

Para tratar de establecer una definición que permita comprender el concepto de familia desde una perspectiva integral, Campos y Smith (1999) señalan algunas variables a tomar en cuenta, como la consanguinidad, la relación conyugal, la estabilidad, la cultura, el parentesco, entre otras; partiendo además de que estas deben organizarse de forma en que faciliten una perspectiva real de lo que es familia. Sobre esta base, una de las concepciones más difundidas la definen como: “(...) unidad básica en la sociedad, unión de personas vinculadas por parentesco biológico o legal, que llena necesidades diversas en el ser humano para su desarrollo integral" (p. 9). Es importante agregar que la familia debe ser concebida no sólo como un espacio en el que sus miembros están unidos por lazos de consanguinidad, sino también por lazos afectivos y por intereses comunes. Y que aunque lo anterior permite hablar de diferentes estructuras familiares, dentro de esta diversidad se pueden señalar características comunes.

Según Campos y Smith (1999), el grupo familiar es interdinámico, lo que le confiere la posibilidad de cambio en referencia a otros grupos familiares de su comunidad y del resto de la sociedad. Además, es intradinámico porque puede cambiar dentro de sí, en las relaciones entre sus componentes, sin afectar demasiado al conjunto de familias del contexto social.

En la actualidad, la sociedad se enfrenta a fuertes y acelerados cambios que permiten señalar el impacto de la globalización y la cultura postmoderna en las diferentes esferas de la vida humana. En el caso de la familia, el concepto y modelo tradicional, proveniente de la ideología patriarcal tan fuertemente arraigada en la cultura de los países centroamericanos, ha dado paso a lo que Hogar y Familia (s.f.) señalan como un nuevo concepto de familia muy heterogéneo.

Ello porque, al igual que la sociedad, la familia se va modificando. En este sentido, su perfil actual podría configurarse según varios aspectos: el incremento de las familias monoparentales, la progresiva pérdida de la autoridad del padre, el aumento de la cohabitación y de los hijos habidos fuera del matrimonio, además del descenso de la fecundidad.

Si bien es cierto, esta pluralidad de modelos familiares que conviven en la actualidad, generan una serie de características y problemáticas sociales que deben ser el centro del debate y la reflexión, tomando en cuenta también 
la particularidad histórico-cultural en que están inmersas; dentro de tanta diversidad se pueden reconocer en la familia, independientemente de su estructura, dinámica o modelo, una serie de funciones esenciales que según Campos y Smith (1999) se pueden clasificar de la siguiente manera:

Función económica: la familia es una célula económica, que como institución social utiliza criterios económicos para definir prioridades y establecer medios para generar ingresos económicos según sus planes y necesidades. Esta función se basa entonces en la generación de ingresos, que además de resolverse por decisiones internas, depende o está condicionada por el momento histórico y las condiciones a nivel social, por los avances tecnológicos, la transculturación, entre otros.

Función de cooperación y cuidado de la salud: es una función compartida con otras instituciones estatales o privadas que nacieron con este fin. Se basa en la seguridad, protección, alimentación, atención médica, entre otras tareas familiares, que responden a su vez, a una concepción sobre salud y enfermedad. Aquí también se toma en cuenta los criterios de cooperación y las pautas sobre cómo, cuándo o hasta dónde se ayuda a cada miembro de la familia con sus tareas, cuáles deben compartirse y en qué condiciones.

Función recreativa: es la familia quien proporciona oportunidades de disfrute y recreación individual y grupal, introduce a sus miembros en las celebraciones y fechas festivas y se encarga de brindar alternativas de esparcimiento sanas o "permitidas" socialmente.

Función afectiva: el ser humano aprende a amar en el seno de la familia y lo que es más importante, ensaya las formas de comunicar afecto desde la más tierna infancia y graba aquellas actitudes que provocan las caricias, y las que producen actos negativos. Lógicamente, este factor es determinante en el desarrollo de la personalidad (Campos y Smith, 1999, p. 21).

Por lo tanto, los códigos para la expresión de sentimientos positivos de amor, solidaridad, compasión y demás emociones afectivas, además de aquellas de índole negativa (odio, rencor, etc.) que se transmiten y aprenden en el núcleo familiar, marcarán la relación de los individuos con la sociedad y con la familia que estos formarán en un futuro.

Función educativa y vocacional: dicha función es compartida con otras instituciones, en una relación que según se ha visto debe ser estrecha, conjunta. La educación como tarea es cotidiana, empieza desde los primeros años de 
vida y continúa reforzándose en años posteriores. Será entonces la familia, la que brinde pautas hacia la formación de sus hijos, sobre su realización profesional, sus valores éticos, morales y determinará en gran parte su desarrollo integral, óptimo.

Función socializadora y de autoidentificación: La familia actúa en un doble proceso de integración social de sus miembros y de desarrollo de la personalidad de estos. La sociedad a su vez, le brinda a la familia los insumos para ejercer la tarea de socialización mediante sus sistemas de costumbres, valores, incentivos o castigos.

En síntesis, la familia transmite estilos de vida, expectativas sociales viables o no, tipos de relaciones interpersonales y demás componentes conocidos como destrezas sociales. En el contexto familiar los individuos desarrollan el sentido de pertenencia, van construyendo su identidad desde el momento en que se les nombra y se les brinda un espacio propio dentro del hogar.

Por eso, es dentro de las actividades familiares cotidianas, donde se desarrolla un contexto educativo informal y el niño y la niña, inmersos en la interacción constante con los otros miembros de la familia y de la comunidad, van construyendo una serie de conocimientos de su mundo social, que luego incorporará a su bagaje cognitivo. Señala el autor que, es así como se puede hablar de la existencia de

(...) una configuración cultural dominante de la familia, en la forma de requisitos en cuanto a la adaptación a un rol. Los roles vitales de la madre, el padre, el hijo y el abuelo sólo adquieren un significado específico dentro de una cultura determinada. La familia modela los tipos de personas que necesita para llevar a cabo sus funciones; los miembros, a su vez gravitan sobre la familia, orientándola hacia la satisfacción de sus objetivos personales. La identidad del individuo necesita el apoyo de la identidad de la familia; a su vez, la identidad de la familia requiere el apoyo de la comunidad que la rodea (p. 16).

Lo anterior permite comprender que la función educativa de la familia dependerá de las demandas y factores históricos, sociales y culturales en las que se gesta y evoluciona. Asimismo en este marco, la estructura familiar, los roles asumidos por sus miembros y las concepciones o imágenes de familia que los individuos construyen, van a responder a necesidades individualizadas, que a su vez se configuran según pautas sociohistóricas. 


\section{Metodología}

Se presentan a continuación aspectos de carácter metodológico que fueron considerados en la investigación que aporta los datos para el presente artículo. El estudio fue de carácter exploratorio-descriptivo que retoma datos de índole cualitativa y se acerca al conocimiento de las nociones en niñas y niños lo cual no se ha profundizado mucho en Costa Rica.

\section{Participantes del estudio}

El estudio se realizó en dos instituciones públicas de la Provincia de San José del circuito 01, catalogadas como escuelas de atención prioritaria. Los participantes fueron diez docentes de educación preescolar de sexo femenino, seleccionadas por estar a cargo de los niños participantes en el estudio o por trabajar en los centros educativos escogidos para la investigación. Todas ellas docentes en propiedad, con grados académicos de Licenciatura (nueve) y Maestría (una).

Por otra parte, las niñas y niños (estudiantes del nivel de transición), fueron inicialmente identificados como costarricenses (hijos o hijas de padres y madres costarricenses) o como extranjeros centroamericanos (hijos o hijas de padres centroamericanos y nacidos en algún país centroamericano). Una vez identificados, se seleccionaron por azar simple. El grupo quedó de la siguiente manera:

\begin{tabular}{|l|c|c|}
\hline Sexo & & $\begin{array}{c}\text { Extranjeros } \\
\text { Centroamericanos*: }\end{array}$ \\
\hline Masculino & Costarricenses & 19 \\
Femenino & 15 & 12 \\
Total & 16 & 31 \\
\hline
\end{tabular}

Una vez realizada la selección, la totalidad de las niñas y los niños que constituyó el grupo de participantes fue de nacionalidad nicaragüense. 


\section{Instrumentos}

Con el fin de recopilar la información para el desarrollo de la investigación, se utilizaron tres técnicas de investigación, específicamente el cuestionario, una entrevista estructurada y la técnica de la representación gráfica de la familia. Estos se describen a continuación.

La utilización del cuestionario respondió al objetivo de identificar el criterio docente acerca de las nociones de familia que poseen los niños costarricenses y extranjeros centroamericanos de 5 a 6 años que estaban a su cargo. Según McKernan (1999):

(...) el enfoque de recogida de datos de los cuestionarios es probablemente el método de investigación más utilizado. Se trata de una forma de entrevista por poderes, que suprime el contacto cara a cara con el entrevistador propio del método de entrevista (...). A la persona que responde se le presenta una lista preestablecida de preguntas que pueden ser de naturaleza abierta o cerrada (p. 145).

Este instrumento fue estructurado por trece preguntas básicas que el docente debía contestar. Las mismas pretendían profundizar acerca del criterio que el docente posee en cuanto a la elaboración de la noción de familia de los niños, los factores que intervienen en dicho proceso, especialmente los de índole cultural y la importancia de conocer dichas nociones y sus diferencias.

También se usó la representación gráfica, instrumento empleado con mucha frecuencia cuando se trabaja con los niños ya que, como señala Vignola (1972), el dibujo es una de las actividades más espontáneas del ser humano, especialmente durante los primeros años de vida, donde se da una autoexpresión relativamente libre. Añade el autor que por medio del dibujo el niño manifiesta su realidad, interpretando de alguna manera el mundo en que vive.

La valoración del dibujo se encuentra en el significado que se le da a las imágenes. Anastasi (1982) recalca que el análisis puede ser cuantitativo o cualitativo, en las características formales y estilísticas que este posea. En el caso de la investigación, realizada buscaba fortalecer el conocimiento mediante la representación gráfica de los niños, la noción que poseen sobre la familia en general y sobre su familia propia, para identificar las características entre estas y los elementos que en general constituyen dicha noción. La representación gráfica en este caso, pretendió ser un elemento más para la comprensión de la noción de familia de los niños participantes. Su análisis 
permitió valorar los miembros representados y su relación desde la perspectiva de los y las participantes.

Para responder a los objetivos de determinar la noción de familia que tenían los niños y las niñas costarricenses de 5 a 6 años, y la noción que al respecto poseían los niños y las niñas extranjeros centroamericanos, se hizo uso de la técnica de la entrevista estructurada. Señala Mckernan (1999) que “(...) el entrevistador tiene una lista de preguntas específicas, un cuestionario administrado oralmente si se quiere. El entrevistador no se aparte de los términos de éstas preguntas" (p. 149).

El instrumento constó de trece ítemes que interrogaban sobre la nacionalidad de la niña o el niño; el país en el que vive; sus ideas en torno a lo que es una familia, cómo está compuesta, la función e importancia de esta y todo lo anterior en función de la propia; además de cuestionar la diferencia entre su familia y la de sus compañeros de otra nacionalidad. Este instrumento se utilizó con el objetivo de que tanto los niños como las niñas expresen las ideas o pensamientos construidos en torno a las nociones de familia que poseen.

Es importante señalar que todos los instrumentos fueron validados en su forma y contenido, median-

Hasta hace algunos años la población estudiantil en las aulas costarricenses se caracterizaba por ser predominantemente de origen costarricense, por lo cual no se contemplaba, explícitamente, la multiculturalidad como un eje trañsversal en la elaboración y desarrollo de los programas de estudio. Sin embargo, actualmente, producto de los cambios socioeconómicos vividos por muchos países latinoa. mericanos, el sistema educativo ha tenido que enfrentar una serie de situaciones o fenómenos (en este caso en, los migratorios) antes no previstos, y que sin duda, tienen grandes repercusiones e implicaciones en los procesos educativos.

te el criterio de jueces, quienes son docentes universitarios con especialidad en Pedagogía, Educación Preescolar y Psicología. Se utilizó un índice de congruencia de 8 .

Es indispensable mencionar que para la investigación, se gestionaron todos los permisos respectivos tanto institucional como individualmente. De igual manera, se ofreció una devolución de resultados a los participantes. 


\section{Resultados}

El análisis de datos se realizó tomando en consideración la información obtenida mediante los instrumentos aplicados para el estudio. En primer lugar y respondiendo a los objetivos de identificar la noción de familia de las niñas y niños costarricenses, la de las niñas y los niños extranjeros centroamericanos; para su respectivo contraste, se muestra la información brindada por los participantes mediante cuadros de frecuencias y porcentajes.

\section{Cuadro 1}

Aspectos y/o personas que los niños costarricenses y extranjeros centroamericanos incorporan al dibujar una familia

\begin{tabular}{|l|c|c|c|c|}
\hline \multirow{2}{*}{ Criterios } & \multicolumn{2}{|c|}{$\begin{array}{c}\text { Costarricenses } \\
(\mathbf{n = 3 1 )}\end{array}$} & \multicolumn{2}{|c|}{$\begin{array}{c}\text { Extranjeros } \\
\text { Centroamericanos } \\
(\mathbf{n = 3 1})\end{array}$} \\
\hline Mamá o Señora & $\mathbf{f}$ & $\%$ & $\mathbf{f}$ & $\%$ \\
Papá o Señor & 22 & $71 \%$ & 22 & $71 \%$ \\
Hijo(s) & 20 & $65 \%$ & 20 & $65 \%$ \\
Hija(s) & 13 & $42 \%$ & 19 & $61 \%$ \\
Otros miembros unidos & 18 & $58 \%$ & 13 & $42 \%$ \\
por lazos de consanguineidad & 16 & $52 \%$ & 20 & $65 \%$ \\
Estructuras físicas o accesorios & 5 & $16 \%$ & 4 & $16 \%$ \\
Se dibuja a sí mismo(a) & 5 & $16 \%$ & 2 & $6 \%$ \\
Animales o plantas & 2 & $6 \%$ & 8 & $26 \%$ \\
Amigos(as)/vecinos(as) & 1 & $3 \%$ & 7 & $23 \%$ \\
Elementos atmosféricos & 3 & $10 \%$ & 3 & $10 \%$ \\
Medios de transporte & - & 1 & $3 \%$ \\
\hline
\end{tabular}


Es interesante señalar que los datos aportados por el cuadro uno, permiten observar que 22 niños costarricenses y 22 extranjeros centroamericanos incorporan como aspectos de la misma a la madre (71\%); asimismo, 20 costarricenses y 20 extranjeros centroamericanos al padre (65\%); hay incorporación de los hijos en ambos grupos (42\%) y 19 extranjeros centroamericanos (61\%); al igual que de las hijas por 18 costarricenses (58\%) y 13 extranjeros centroamericanos $(42 \%)$. Suelen también incorporar en sus dibujos a otros miembros de la familia unidos por lazos de consanguineidad 16 costarricenses $(52 \%)$ y 20 extranjeros centroamericanos $(65 \%)$.

$\mathrm{Al}$ analizar otros elementos incorporados en los dibujos, es posible señalar que 5 costarricenses (16\%) y 2 extranjeros centroamericanos $(6 \%)$ se dibujan a sí mismos; los animales o las plantas fueron dibujadas por 3 costarricenses y 8 extranjeros centroamericanos. Esta situación se acentúa cuando se trata sobre el criterio de amigos o vecinos donde un costarricense (3\%) lo incorpora, así como siete extranjeros centroamericanos (23\%). Por otra parte, hay elementos atmosféricos (nube, arcoiris, sol) que son añadidos al dibujo de la familia ( 3 costarricenses y 3 extranjeros centroamericanos). Sólo un extranjero centroamericano incorpora un medio de transporte (barco) a su dibujo.

Es posible observar que existe una gran similitud entre los niños costarricenses y extranjeros centroamericanos al dibujar a los miembros que, según ellos, forman parte de una familia. Sin embargo, se presenta una tendencia más marcada, en los extranjeros centroamericanos, por incorporar a otras personas, animales u objetos al grupo familiar.

Esta tendencia ha sido retomada por la literatura cuando se plantea las repercusiones de los factores externos, como el económico, a la composición familiar. Ackerman (citado por Carvajal y Guang, 2003), amplía este aspecto al considerar que las características de la familia varían de acuerdo con las condiciones sociales y culturales que la determinen. De ahí que las condiciones vividas determinen lo que para cada grupo social es importante que forme parte de una familia.

El cuadro 2 recopila la cantidad de miembros que conforman la familia propia, según lo representado por niños costarricenses y extranjeros centroamericanos. La graficación de la familia propia con 1 ó 2 miembros es realizada por 4 costarricenses (13\%) y 3 extranjeros centroamericanos (10\%). De 3 a 4 miembros son dibujados por 14 costarricenses (45\%) y 16 extranjeros centroamericanos (52\%), esta es la categoría que recopila la mayoría de expresiones gráficas en ambos grupos. 


\section{Cuadro 2}

Cantidad de miembros que conforman la familia propia, según lo representado por los niños costarricenses y extranjeros centroamericanos

\begin{tabular}{|c|c|c|c|c|}
\hline \multirow[b]{2}{*}{ Número de integrantes } & \multicolumn{2}{|c|}{$\begin{array}{c}\text { Costarricenses } \\
(\mathrm{n}=31)\end{array}$} & \multicolumn{2}{|c|}{$\begin{array}{l}\text { Extranjeros } \\
\text { Centroamericanos } \\
(n=31)\end{array}$} \\
\hline & $\mathrm{f}$ & $\%$ & $f$ & $\%$ \\
\hline 1 a 2 miembros & 4 & $13 \%$ & 3 & $10 \%$ \\
\hline 3 a 4 miembros & 14 & $45 \%$ & 16 & $52 \%$ \\
\hline 5 a 6 miembros & 12 & $39 \%$ & 9 & $29 \%$ \\
\hline 7 a 8 miembros & - & - & 2 & $6 \%$ \\
\hline 9 a 10 miembros & - & - & 1 & $3 \%$ \\
\hline Más de 11 miembros & 1 & $3 \%$ & 1 & $3 \%$ \\
\hline
\end{tabular}

En la categoría de 5 a 6 miembros, se encuentran 12 costarricenses (39\%) y 9 extranjeros centroamericanos (29\%). Por lo que se puede decir que las tres categorías anteriores tienen frecuencias muy similares para los niños de ambas nacionalidades.

Los intervalos correspondientes entre 7 y 11 miembros, aunque en menor frecuencia, son de expresiones gráficas de niños extranjeros centroamericanos, ya que únicamente la representación de un costarricense aparece en la categoría de más de 11 miembros.

Por lo anterior, las representaciones de ambos grupos de niños permiten afirmar que la diversidad es una característica presente en la constitución familiar de los participantes. Sin embargo, diversos factores socioculturales y económicos podrían estar influyendo en dicha constitución, en el caso de los niños extranjeros centroamericanos, de ahí que sea este grupo el que representa un modelo familiar constituido por una mayor cantidad de miembros. 


\section{Cuadro 3}

Respuesta a la pregunta ¿quiénes forman una familia?, brindada por niños costarricenses y extranjeros centroamericanos

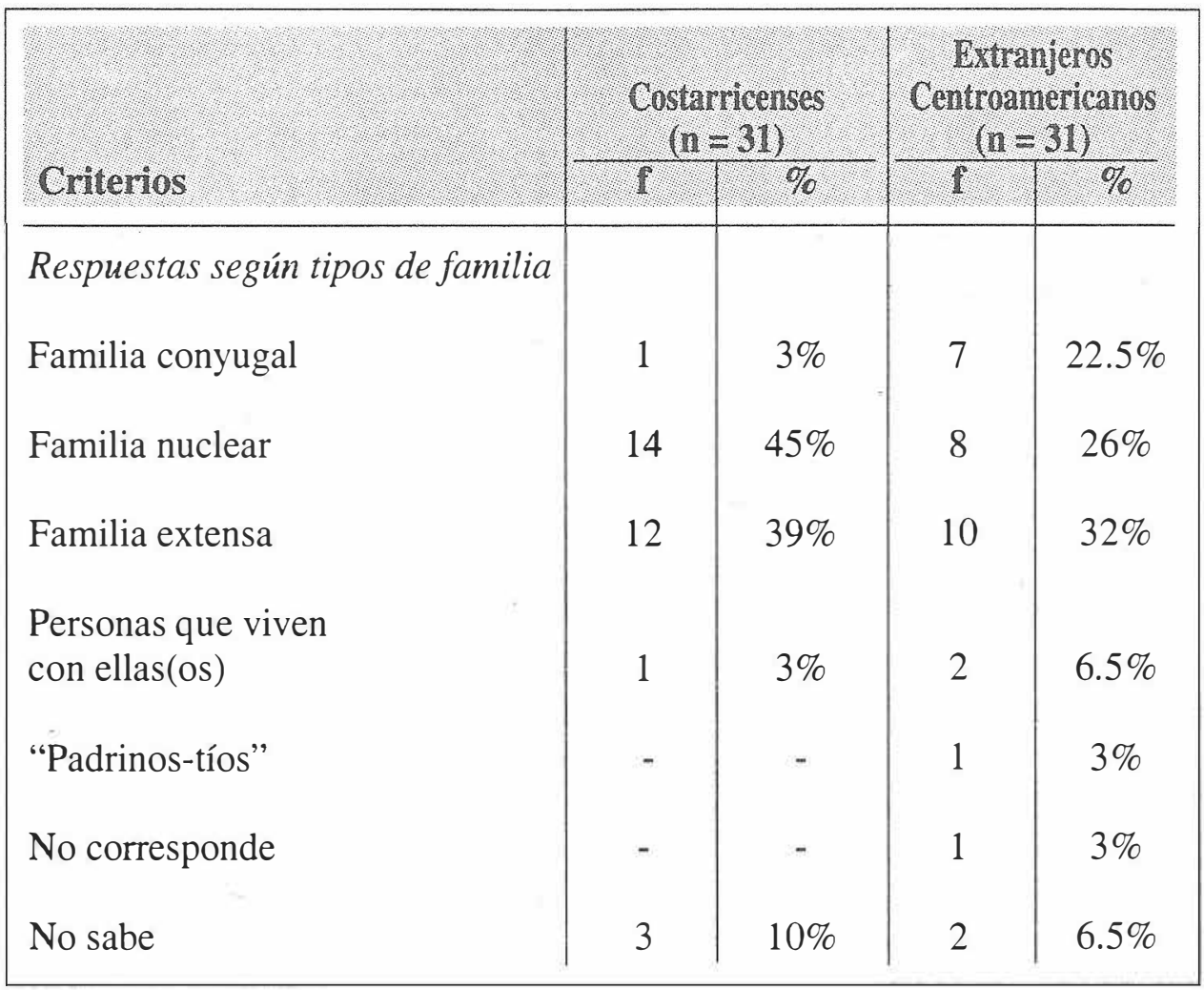

El cuadro 3 muestra que las respuestas brindadas por los niños se han categorizado según diversos tipos de familia. De acuerdo con dichas categorías, un costarricense (3\%) y 7 extranjeros centroamericanos $(22.5 \%)$ se refïeren a una familia de tipo conyugal, 14 niños costarricenses (45\%) y 8 extranjeros centroamericanos (26\%) hablan de una familia nuclear. Se refieren a una familia de tipo extensa 12 costarricenses (39\%) y 10 extranjeros centroamericanos (32\%).

En menor cantidad, un costarricense (3\%) y dos extranjeros centroamericanos $(6.5 \%)$ mencionan que han dibujado a las personas que viven con ellos. Solamente un extranjero centroamericano (3\%) habla de "padrinos, tíos". Además, un extranjero centroamericano (3\%) dio una respuesta que no corresponde a la pregunta y 3 costarricenses (10\%), 2 extranjeros centroamericanos $(6.5 \%)$ responden que no saben. 
Es importante señalar que en todas las categorías anteriores tanto niños costarricenses como extranjeros centroamericanos, utilizaron en sus respuestas pronombres posesivos, por ejemplo 6 niños costarricenses y 4 extranjeros centroamericanos responden a la pregunta diciendo "mi papá, mi mamá, mis hermanos", a diferencia de 8 niños costarricenses y 4 extranjeros centroamericanos que responde diciendo "el papá, la mamá, los hermanos".

De lo anterior, resulta interesante el hecho de que en el caso de los niños extranjeros centroamericanos, parece haber mayor inclinación a identificar al papá y la mamá como los miembros de una familia, produciéndose la exclusión de sí mismos como hijos y la de otros miembros. Sin embargo, en las categorías de familia nuclear (papá, mamá, hijos) y familia extensa (papá, mamá, hijos, abuelos, tíos), las frecuencias permiten hablar de una noción de familia similar en ambos grupos, que podría responder a un proceso de conceptualización donde aún dominan los aspectos perceptuales. En este caso, la constitución de familia va a estar influenciada por características propias del contexto en que ambos grupos se desenvuelven, tomando en cuenta que pertenecen a la misma comunidad y a una condición socioeconómica similar.

Al tratar de conceptuar quiénes conforman una familia, ambos grupos de niños recurren a la descripción de su propio núcleo familiar (utilizan pronombres posesivos) o a las familias que les rodean (familias de origen costarricense y de origen extranjero). Es importante hacer notar que al ser niños en el periodo preoperacional (según la teoría Piagetiana), su pensamiento aún es restringido, pero ya han desarrollado cierta capacidad simbólica que les permite realizar esfuerzos de abstracción, por lo que en este caso únicamente 5 niños expresan no saber la respuesta (cuadro 4).

Según cuadro 4 , se puede observar que en cuanto a con quien viven los niños, 19 costarricenses (61\%) y 17 extranjeros centroamericanos $(55 \%)$ refieren a la familia nuclear, en este mismo sentido un costarricense y un extranjero centroamericano (3\%) en cada caso, aluden a una familia nuclear con un padrastro. Asimismo, 6 costarricenses (19\%) y 9 extranjeros centroamericanos (29\%) mencionan a la familia extensa; mientras que un costarricense y un extranjero centroamericano (3\%) una familia extensa incluyendo miembros sin relación consanguínea.

Puede decirse, entonces, que existen similitudes entre los miembros de las familias con quienes viven los preescolares, costarricenses y extranjeros centroamericanos, respecto a la familia nuclear, la familia compleja y la monoparental. La mayor diferencia que se presenta entre los niños participantes en el estudio se debe a que la mayoría de los niños costarricenses (29\%) 


\section{Cuadro 4}

Respuesta a la pregunta ¿con quién vive usted?, brindada por niños costarricenses y extranjeros centroamericanos

\begin{tabular}{|c|c|c|c|c|}
\hline \multirow[b]{2}{*}{ Criterios } & \multicolumn{2}{|c|}{$\begin{array}{l}\text { Costarricenses } \\
\qquad(\mathbf{n}=31)\end{array}$} & \multicolumn{2}{|c|}{$\begin{array}{l}\text { Extranjeros } \\
\text { Centroamericanos } \\
(\mathrm{n}=31)\end{array}$} \\
\hline & i & 1.9 & $=\frac{f}{f}$ & $\%$ \\
\hline \multicolumn{5}{|c|}{ Respuestas según tipos de familias } \\
\hline Familia nuclear & 19 & $61 \%$ & 17 & $55 \%$ \\
\hline $\begin{array}{l}\text { Familia nuclear } \\
\text { (padrastro) }\end{array}$ & 1 & $3 \%$ & 1 & $3 \%$ \\
\hline Familia extensa & 6 & $19 \%$ & 9 & $29 \%$ \\
\hline $\begin{array}{l}\text { F. extensa incluyendo } \\
\text { miembros sin relación } \\
\text { consanguínea }\end{array}$ & 1 & $3 \%$ & 1 & $3 \%$ \\
\hline Familia Monoparental & 4 & $13 \%$ & 3 & $10 \%$ \\
\hline
\end{tabular}

cuenta con una familia nuclear, frente a un menor porcentaje en los niños extranjeros centroamericanos (55\%).

Asimismo, de este último grupo, una mayoría refleja familia extensa, a diferencia de los 9 niños costarricenses que lo refirieron (19\%). Lo anterior probablemente debido a la estructura familiar asumida por cada grupo, la cual se ve configurada por pautas sociales, culturales y económicas. Al respecto, Ackerman (citado por Carvajal y Guang, 2003), considera que la cultura es un factor dominante en la configuración de la estructura familiar; por tanto, esta va a determinar cada modelo familiar, como en el caso de los participantes el que un grupo (extranjeros centroamericanos) esté constituido por una mayor cantidad de miembros que el otro (costarricenses). 


\section{Cuadro 5}

Respuesta a la pregunta ¿cómo es su familia?, brindada por niños costarricenses y extranjeros centroamericanos

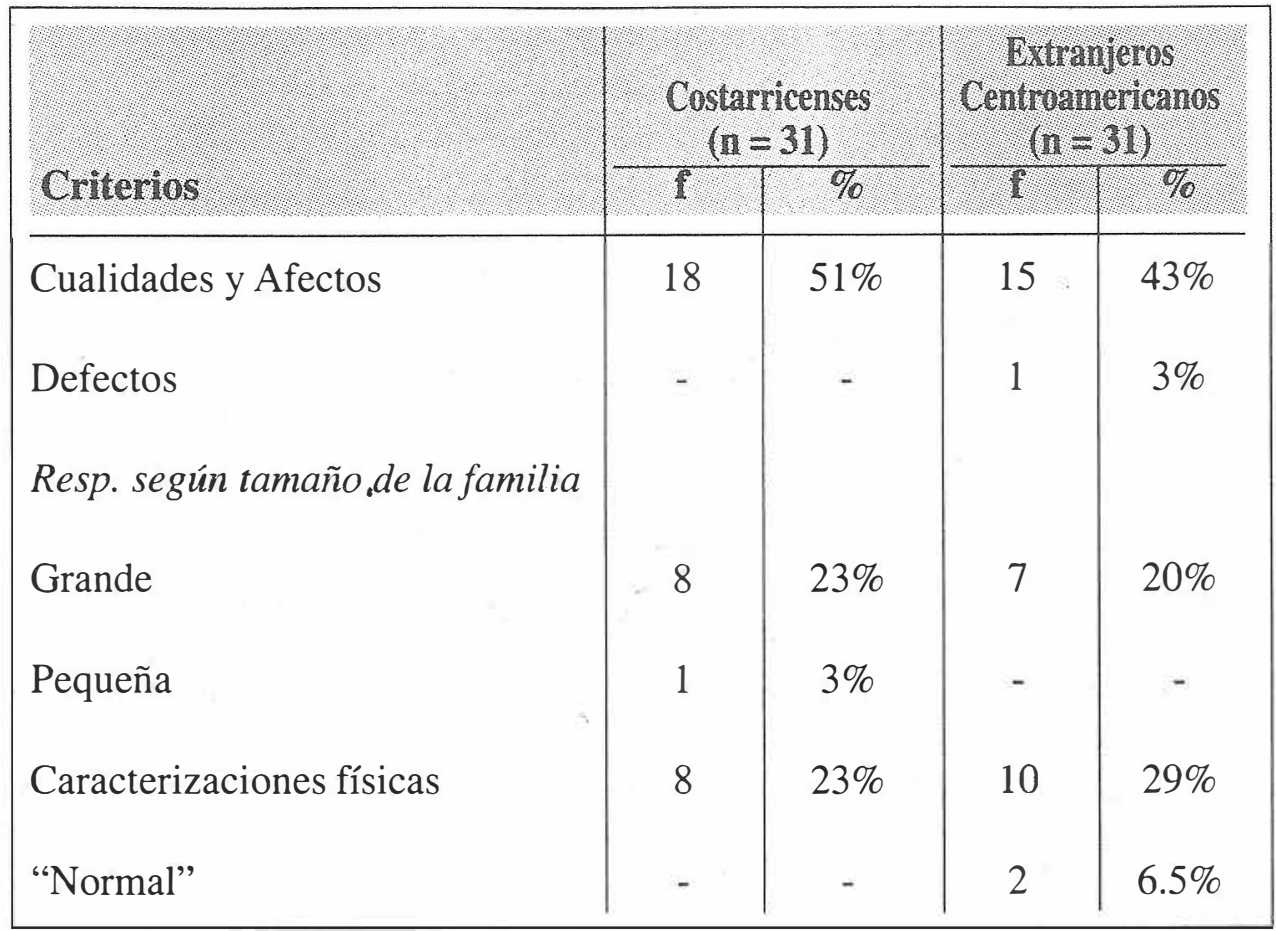

Del cuadro anterior se desprenden las caracterizaciones que hacen los niños de ambos grupos de su familia, 18 costarricenses (51\%) y 15 extranjeros $(43 \%)$ se refieren a cualidades y afectos; por otra parte, un extranjero centroamericano lo hace con defectos.

Según el tamaño de la familia, 8 costarricenses (23\%) y 7 extranjeros (20\%) la caracterizan grande, mientras sólo un costarricense (3\%) como pequeña. Otro criterio expresado por los niños fue las caracterizaciones físicas por parte de 8 costarricenses (23\%) y 10 extranjeros centroamericanos (29\%). Por su parte, 2 extranjeros centroamericanos $(6.5 \%)$ las calificaron como normales, sin aclarar lo que entienden por ese calificativo.

Al señalar cómo es su familia, existe similitud tanto entre las respuestas brindadas por los niños costarricenses como por los extranjeros centroamericanos, respecto a lo que entienden por tamaño de la familia y lo que según ellos es normal. Se encontró una leve diferencia en el hecho de que las cualidades y los afectos son más importantes para los costarricenses que para los extranjeros centroamericanos, quienes manifestaron mayor atención. 
Es importante rescatar que según la FLACSO y OIM (citados por Arce 2003) las personas migrantes deben enfrentarse a situaciones de discriminación y rechazo, ya sea por su aspecto físico, su acento, entre otras; situación que cobra gran relevancia para este grupo, pues podría estar mediando la importancia que estos aspectos tienen para los extranjeros centroamericanos participantes en el estudio.

\section{Cuadro 6}

Respuesta a la pregunta ¿quiénes forman parte de su familia?, brindada por niños costarricenses y extranjeros centroamericanos

\begin{tabular}{|c|c|c|c|c|}
\hline \multirow[b]{2}{*}{ Criterios } & \multicolumn{2}{|c|}{$\begin{array}{l}\text { Costarricenses } \\
:(\mathbf{n}=31)\end{array}$} & \multicolumn{2}{|c|}{$\begin{array}{l}\text { Extranjeros } \\
\text { Centroamericanos } \\
(n=31)\end{array}$} \\
\hline & I: & $\%$ & $f$ & $\%$ \\
\hline \multicolumn{5}{|c|}{ Da respuesta según tipos de familia } \\
\hline Familia monoparental & - & - & 1 & $3 \%$ \\
\hline Familia de un abuelo & 2 & $6 \%$ & - & - \\
\hline Familia nuclear & 20 & $65 \%$ & 6 & $19 \%$ \\
\hline $\begin{array}{l}\text { Familia nuclear } \\
\text { con un padrastro }\end{array}$ & - & - & 1 & $3 \%$ \\
\hline Familia extensa & 8 & $26 \%$ & 15 & $48 \%$ \\
\hline $\begin{array}{l}\text { Familia extensa } \\
\text { incluyendo animales }\end{array}$ & - & - & 1 & $3 \%$ \\
\hline $\begin{array}{l}\text { Abuelo, abuela } \\
\text { y unas tías }\end{array}$ & - & - & 1 & $3 \%$ \\
\hline Familia compleja & - & - & 4 & $13 \%$ \\
\hline Todos & - & - & 2 & $6 \%$ \\
\hline Nadie & 1 & $3 \%$ & - & - \\
\hline
\end{tabular}


De las respuestas brindadas por los niños y las niñas en el cuadro 6, se puede realizar la siguiente categorización según los tipos de familia: solamente un niño extranjero centroamericano (3\%) forma parte de una familia monoparental, únicamente 2 niños costarricenses (6\%) forman parte de una familia encabezada por el abuelo, 20 niños costarricenses (65\%) y 6 extranjeros centroamericanos (19\%) viven en una familia nuclear; un extranjero centroamericano (3\%) forma parte de una familia nuclear con un padrastro, 8 costarricenses $(26 \%)$ y 15 extranjeros centroamericanos (48\%) tienen una familia extensa.

Además, un niño extranjero centroamericano (3\%) forma parte de una familia extensa e incluye animales dentro de ella y otro niño extranjero centroamericano (3\%) tiene como familia únicamente a su abuelo, abuela y tías. En cuanto a familias complejas, 4 niños extranjeros centroamericanos (13\%) se ubican dentro de esta categoría, 2 extranjeros centroamericanos (6\%) mencionan "todos" en su respuesta y 1 niño costarricense (3\%) expresa que "nadie" forma parte de su familia.

Por lo anterior, en este cuadro se nota que una importante cantidad de los preescolares costarricenses incluyen como parte de su familia únicamente al padre, la madre y hermanos. Mientras que los niños extranjeros centroamericanos mencionan mayoritariamente a diversas personas dentro de su familia: padre, madre, hermanos, abuelos, tíos, sobrinos e incluso a personas con las que no tienen ningún vínculo consanguíneo.

Es así como las palabras de Ackerman (citado por Carvajal y Guang, 2003, p. 7) encuentran significatividad, al afirmar que "(...) las formas específicas de la familia varían de acuerdo con la cultura". Y en especial si se considera que estos niños forman parte de una comunidad donde interactúan diversas culturas, el patrón familiar costarricense que históricamente ha prevalecido en Costa Rica es el que encabeza en las respuestas de los niños costarricenses. Mientras que en el caso de los niños extranjeros centroamericanos, las demandas y factores sociohistóricos y económicos crean las condiciones para que la constitución de sus familias responda a sus valores y necesidades particulares como una población inmigrante.

En el cuadro 7 los resultados reflejan las razones que brindan los niños para justificar la importancia de la familia. Así por ejemplo 23 costarricenses $(68 \%)$ y 16 extranjeros centroamericanos (40\%) dan razones afectivas; seis costarricenses $(18 \%)$ y 12 extranjeros centroamericanos $(30 \%)$ razones físicas; por otro lado, dos costarricenses (6\%) y 5 extranjeros centroamericanos (12.5\%) mencionan razones materiales; sólo 4 extranjeros centroamericanos 


\section{Cuadro 7}

Respuestas brindadas por niños costarricenses y extranjeros centroamericanos acerca de las razones para considerar importante a la familia

\begin{tabular}{|c|c|c|c|c|}
\hline \multirow[b]{2}{*}{ Criterios } & \multicolumn{2}{|c|}{$\begin{array}{l}\text { Costarricenses } \\
(\mathrm{n}=31)\end{array}$} & \multicolumn{2}{|c|}{$\begin{array}{l}\text { Extranjeros } \\
\text { Centroamericanos } \\
\qquad(\mathbf{n}=31)\end{array}$} \\
\hline & f & $\%$ & $f$ & $1 \%$ \\
\hline Por razones afectivas & 23 & $68 \%$ & 16 & $40 \%$ \\
\hline Por razones físicas & 6 & $18 \%$ & 12 & $30 \%$ \\
\hline Por razones materiales & 2 & $6 \%$ & 5 & $12.5 \%$ \\
\hline Por razones recreativas & - & - & 4 & $10 \%$ \\
\hline Por razones educativas & - & - & 1 & $2.5 \%$ \\
\hline "Vivir" & - & - & 1 & $2.5 \%$ \\
\hline No sabe/ no responde & 3 & $9 \%$ & 1 & $2.5 \%$ \\
\hline
\end{tabular}

(10\%) indican razones recreativas y un extranjero centroamericano $(2.5 \%)$ razones educativas. Un extranjero centroamericano (2.5\%) consideran importante la familia para vivir y 3 costarricenses ( $9 \%$ ) y un extranjero centroamericano $(2.5 \%)$ no saben o no responden.

Es importante rescatar que al consultarles a los niños acerca de la importancia de la familia, los costarricenses le dan prioridad a las razones afectivas, mientras que el grupo de niños extranjeros centroamericanos destaca las razones físicas, en cuanto a la protección y la seguridad que según ellos se les debe brindar. Los porcentajes restantes respecto a las otras razones brindadas son muy similares en ambos grupos. Cabe mencionar que la diversidad es latente no solo en la conformación, sino también en la dinámica y función del grupo familiar de los niños participantes en el estudio. 


\section{Conclusiones}

A continuación, se presentan las conclusiones derivadas de los resultados de esta investigación. Con respecto a los objetivos de la investigación que buscaban determinar la noción de familia que tienen los niños costarricenses y los niños extranjeros centroamericanos participantes, para posteriormente realizar un contraste entre ellas, se puede concluir lo siguiente:

- Los niños y las niñas costarricenses y extranjeros centroamericanos, como seres sociales que dependen de las personas significativas que les rodean desde su nacimiento para sobrevivir y desarrollarse, reconocen la importancia de la familia independientemente del marco cultural y el modelo familiar al que pertenecen.

- En cuanto a la estructura familiar que forma parte esencial de la noción de familia de los y las infantes preescolares, en el caso de la constitución de las familias propias en las que viven, la familia nuclear es el modelo tradicional que sigue imperando en el grupo de los niños y niñas costarricenses, mientras que en los extranjeros centroamericanos es la familia extensa. Sin embargo, en la noción de una familia "imaginaria", el modelo de familia extensa se presenta en una cantidad similar en ambos grupos y casi con la misma frecuencia que el modelo nuclear en el caso de los niños y niñas costarricenses. Por tal razón, se puede hablar del contexto sociocultural mediato e inmediato como factores que confluyen en la noción de familia de las niñas y los niños participantes. De tal forma, que no sólo la realidad familiar propia, sino también la diversidad de modelos familiares dentro de la comunidad en la que conviven, son referentes del medio social que los infantes incorporan dentro de su noción de familia.

- Tanto los y las infantes costarricenses como los extranjeros centroamericanos poseen costumbres y tradiciones propias de la cultura a la cual pertenecen, lo que crea diferencias en los conocimientos que construyen los niños y las niñas de ambos grupos sociales. Lo anterior se evidencia al comprobar que la mayoría de estos costarricenses han elaborado una noción de familia que depende en gran medida, de su realidad familiar en cuanto a la constitución, en el sentido de que priorizan en los miembros que la conforman, este aspecto se ve reflejado de igual manera en una minoría de niñas y niños extranjeros centroamericanos. Sin embargo, este último grupo se centró más en aspectos de relaciones afectivas (ya sea sentimientos positivos o negativos) para referirse a la 
noción de familia, lo que se manifiesta en una minoría de los estudiantes costarricenses.

- En el proceso de desarrollo cognitivo de los y las discentes participantes, resulta importante retomar los aportes piagetianos para comprender que la noción de familia que los y las infantes elaboran es característica de la etapa preoperacional, por lo que para ellos, las funciones de la familia y su estructura son elementos claramente identificables, por estar vinculados con su realidad concreta, sus vivencias diarias y sus necesidades básicas. No obstante, aún existen limitaciones en su capacidad de abstracción reflexiva, por lo que el aspecto del origen de la familia representa un conflicto cognitivo que "resuelven" utilizando una reflexión más de tipo empírica.

- La frecuencia en que los niños y las niñas costarricenses y los extranjeros centroamericanos se dibujan a sí mismos en la representación gráfica de la familia propia, es muy similar. Es interesante también, que casi la mitad de los y las participantes no se incorporan en dicho dibujo, lo que entre otras cosas, bien podría indicar que estos se toman como un referente para dibujar a aquellas personas significativas que conviven con ellos.

- Las y los estudiantes extranjeros centroamericanos incorporan con mayor frecuencia otros elementos (animales, plantas, medios de transporte) y miembros (amiga/compañero) en el dibujo de la familia propia; esto podría ser una expresión de una mayor valoración de dichos elementos, cuya significación estaría relacionada a desprendimientos, pérdidas o ganancias que por su condición de inmigrantes han experimentado.

\section{GLOSARIO}

Noción: Son ideas o esquemas representativos que el niño emplea y que se basan en imágenes de un grupo determinado de objetos (Piaget, citado por Marchesi, 1992).

Extranjero Centroamericano: Se entendió como extranjero/a centroamericano /a , al niño o niña de edad preescolar (5-6 años) procedente de algún país centroamericano y de padres extranjeros centroamericanos y que cursa estudios en un jardín de niños infantil público en Costa Rica.

Familia: Es un conjunto de elementos (personas con lazos consanguíneos y no consanguíneos) que interactúan entre sí (relación afectiva, económica, moral y espiritual), planeada su orientación hacia una o varias metas, teniendo como fin principal la plena realización como persona de cada uno de sus rriembros (García, citado por Aguilar, 1997). 


\section{REFERENCIAS}

Aguilar, H. (1997). La magia de compartir con nuestros hijos. Costa Rica: Progreso Editorial.

Anastasi, A. (1982). Tests Psicológicos. Barcelona: Ediciones Españolas.

Arce, D., Carballo, A., Castro, K y Pereira, Z. (2004). La noción de familia que tienen niños costarricenses y extranjeros centroamericanos que asisten a un Jardín Infantil Público. Seminario de Licenciatura no publicado. Universidad Nacional, Heredia, Costa Rica.

Arce, K. (2003). Estudio de necesidades educativas de los inmigrantes nicaragüenses y una propuesta de modelo curricular en la Escuela Santa Isabel, del circuito 01 Venecia de la Regional de San Carlos. Tesis de Licenciatura no publicada. Universidad Estatal a Distancia, San José, Costa Rica.

Arnaiz, P. (1999). El reto de educar en una sociedad multicultural y desigual. En línea. Disponible en: www.paidos.redins.es/needirectorio/meiu4htm

Azofeifa, F.; Céspedes, E; Monge, M y Vidal M. (2001). Diversidad e Integración Cultural. Heredia: Organización Internacional para los Migrantes, Ministerio de Educación Pública y Universidad Nacional.

Brenes, G. (1999). Estimulación del volumen y características sociodemográficas de los inmigrantes nicaragüenses en Costa Rica. Tesis de Licenciatura no publicada, Universidad de Costa Rica, San José.

Campos, C. y Smith, M. (1991). Técnicas de diagnóstico familiar y comunal. San José, Costa Rica: Editorial Universidad Estatal a Distancia.

Carvajal, R. Y Guang, E. (2003). Compendio de lecturas del curso Psicología de la Familia. Heredia: Universidad Nacional.

Dengo, M. (1995). Educación Costarricense. San José, Costa Rica. Universidad Estatal a Distancia.

Ebanks, E. (1993). Determinantes socioeconómicos de la migración interna. Chile: Centro Latinoamericano de Estadística.

Facultad Latinoamericana de Ciencias Sociales. (1999). Amnistía migratoria en Costa Rica. Costa Rica: Facultad Latinoamericana de Ciencias Sociales.

García, F., Pulido, R. y Montes, A. (2002). "La educación multicultural y el concepto de cultura". En: Revista Iberoamericana de Educación. $\mathrm{N}^{\circ}$ 13. Organización de Estados Iberoamericanos CEI. (En línea). Disponible en: www.oei.org.co/ oeivirt/riel.htm.

Gimeno, J. (2001). La educación obligatoria: su sentido educativo y social. Madrid: Ediciones Morata.

Marchesi, A (1992). Desarrollo de los procesos cognitivos en psicología evolutiva y educación preescolar. México: Editorial Santillana.

Mckernan, J. (1999). Investigación-acción y currículum. Madrid: Ediciones Morata. 
Meléndez, L. (2000). Educación para la diversidad en una sociedad para el conocimiento. Conferencia impartida en la Universidad Interamericana, "Cómo aprende el ser humano: construyendo ambientes educativos".

MEP/IOM/AID. (2000-2001). Diversidad e integración cultural. Programa de Educación. 1a. ed. San José, Costa Rica.

Recasens, J. (2001). Multiculturalidad e interculturalidad. (en línea). Disponible: www.rehue.csociales.uchiled/personales, arecasens/multicult.htm-100k. 